\title{
USER PATTERNS: OUTDOOR SPACE AND OUTDOOR ACTIVITIES
}

\author{
Sakhri Hadjira ${ }^{1,2}$, Bada.Yassine ${ }^{1}$, Rohinton.Emmanuel ${ }^{2}$ \\ Zahariade Ana Maria ${ }^{3}$
}

Key words: outdoor space, human Behaviors, Activities, Climate, Space use.

\begin{abstract}
The understanding of the relationship between outdoor activities and outdoor urban spaces is a complex issue, comprising a mutual study between urban space configuration and human behaviors aspect. Jan Gehl and Birgitte Svarre 1987 confirmed that when the outdoor areas are of high quality, the outdoor activity take place with the same frequency, and they tend to take a longer time. From this point, this paper presents an investigation method of the quality of outdoor urban space basing on the investigation of user pattern. El-Houria plaza in Biskra city, Algeria was chosen as case study. Behavioral mapping and questionnaire survey were applied, for data collection and analysis on March, where the mean daily maximum temperature in the city is $24^{\circ} \mathrm{C}$. The findings from this study show that there is a segregation in the continuity of outdoor activities during the day, due to the poor quality of plaza, as well as this confirmed that the continuity of outdoor activities in space is depend on the quality of outdoor urban space. This investigation method can be used it and applied to analysis user pattern and examine the quality of outdoor urban space to lead and prompt to a successful design.
\end{abstract}

\section{Introduction}

Public space the stage upon which the drama of communal life unfolds (Carr et al, 1992). It concerns not only the physical but also the psychological and the sociological dimensions, this means that public spaces are capable to effect on the

\footnotetext{
${ }^{1}$ Laboratory of design and modeling of architectural ambiances and urban forms (LACOMOFA), Departement of Architecture, University of Mohamed Khider Biskra, Algeria. hadjira.sakhri@univbiskra.dz,yassinebada@yahoo.fr.

${ }^{2}$ Department of Construction and Surveying, Glasgow Caledonian University, United Kingdom, Rohinton.Emmanuel@gcu.ac.uk

${ }^{3}$ Doctoral School of Architecture, Ion Mincu University of Architecture and Urbanism, Bucharest, Romania, zahariade.mail@gmail.com
} 
way people behave, experience and interact in public spaces (Aghostin, 2007) "We shape our space, thereafter, our space shapes us." (Winston Churchill, 1943).

The term of user patterns was originally inspired by the work of the British architect Christopher Alexander, he was the first who describe what he called "a pattern language", which map various problems in building architecture to offer solution. In geography, ecology and landscape ecology "spatial pattern" is a popular term, and basically means the organization and placement of people and objects on earth. In this study, we use the term "user pattern" to describe the way of people's distribution in outdoor urban space.

Several behavioral studies in urban open spaces have contributed importantly to the understanding of the interaction between user pattern and urban open space. According to Gehl 1971 outdoor activities in outdoor spaces can be divided into three categories, dependent on different conditions of the physical environment; necessary activities, optional activities, and social activities. William Whyte is one of the pioneers of this study by observing and mapping people's preferences, activities and interactions, especially in the streets of New York. Among 133 conversations mapped, 57 were recorded in the busiest areas evaluated, Whyte found that seating availability highly influenced the presence of users, people tend to sit most where there are places to sit (Whyte 2012). Bill Hillier and Julienne Hanson (1984) in the book of " the social logic of space" introduced the concept of space syntax a theory and a method to look into the correlation between people behavior, and the space layout, the basis goal is to evaluate the movement patterns of people in real life (Hillier et al 1984), Choi et al (2006)in their study of urban space in Seoul, Korea used space syntax theory to analysis, regarding the pedestrian movement to defined the lighting system of city ,the major aimed of this study is to improve the safety of street. Bada (2012), investigated the correlation between people's movement and spatial use, in four plazas in the city center of Biskra, Algeria, using space syntax method, the results of this study showed that the spatial use is strongly related to visual considerations relevant to the type of activity.

The study of human behaviors in outdoor spaces can conducted by registering of user activities by hand on paper, time lapse photography, motion pictures, video tape and geographies system (Nasar \& Yurdakul 1990, Li, 1994, Nikolopoulou et al, 2001, Zacharias et al, 2001, Campos, 2005, Thorsson et al 2007, Goličnik et al, 2010, Maruši, 2011, Martinelli et al, 2015, Jayasundara 2016).

The understanding of the relationship between outdoor spaces and outdoor activities has attracted planners, designers, decision makers and authorities, the aim was to use the knowledge of human behavior while designing outdoor spaces, however in this paper we are looking to study this relationship to examine the 
quality of outdoor space by investigation of outdoor activities on term of static and dynamic activities and approach this issue to the perspective of urban life quality.

\section{Methodology}

\subsection{Study area}

Biskra is one of the largest city in Algeria, it is located at latitude $34^{\circ} 5^{\prime \prime} \mathrm{N}$ and longitude $5^{\circ} 4 \mathrm{E}$ ", the city is called the "Gate of the Sahara" and it is known by its hot and arid climate. El Houria Plaza was chosen as case study, for its strategic location in the city center. The plaza characterized by the frequent use, and the services available such as cafes and shops, its layout is mainly characterized by two-level space: the higher section limited on East-west by El Amir Abdelkader Boulevard, the most livable boulevard in the city, and the lower section limited by a busy street that links it with a popular market (Fig. 1). The height difference between the two levels is about 1.20 meters, and the connection is assured by a series of stairs without causing any visual obstruction within the plaza.

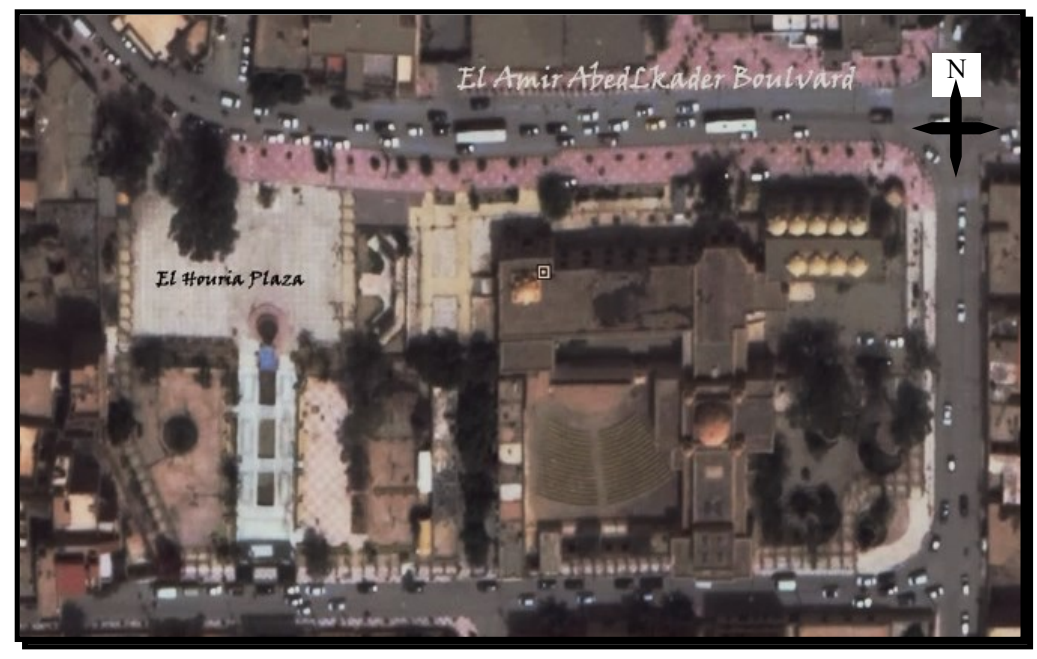

Fig. 1. Ground plan of El-Houria Plaza (Google Earth, 2019)

\subsection{Material and method}

The data was collected through fieldwork in two steps, using objective and subjective mixed methods. The first step consisted unobtrusive observation and mapping the human behavior using hand, paper, time lapse and video photography, this step aimed to analysis the user pattern in the real time such as the frequency distribution of activities and people's occupancy during the day. The second step consisted a questionnaire survey of users and using SPSS (Statistical Package for 
the Social Science) software to analysis people's response. In this study, the observation of human behavior was based on the theoretical aspect extracted by the literature review, it was consisted observed and mapping the user pattern; siting, standing and walking simultaneously (Fig. 2).

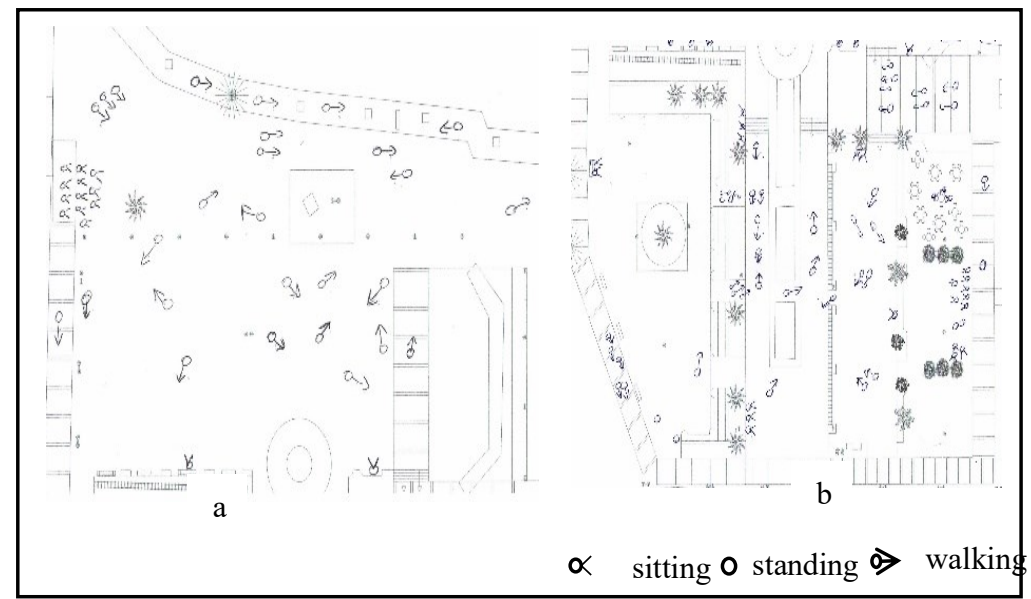

Fig. 2. Example of behavioral mapping drawing by observed, (a) the higher space, (b) the lower space

The observation was carried into two days' weekday and week end on March, from 7 to $10 \mathrm{~min}$ in five different time periods 8 -10h (morning rush hour), 10-12h (midi morning period), 12-14h (lunchtime peak), 14-16h (midi afternoon period), 16-18h (evening rush hour), in order to cover both busy and quiet times on the day. On March the mean daily maximum temperature in the city is $24^{\circ} \mathrm{C}$.

On parallel with the observation, a questionnaire survey was carried out, the goal of this step is to approach the obtained results from behavioral mapping to user's perception. The questionnaire consists a series of questions about people's outdoor activities in plaza, it was divided into three parts. The first part investigated the demographic data related to the respondents such as, age, gender and type of activity. The second part consisted the characteristic of the physical environment of plaza such as the attractivity and the choice to use it. The third part focused on the preferences time to use the plaza by respondent.

\section{Results and discussion}

The first results from the behavioral mapping showed that there is a difference on people's occupancy according to the spatial layout of plaza in one hand (Fig. 3) 
and according to the time of the day in other hand (Tab. 2). The upper zone of plaza is connected directly to the major boulevard East -West, and it is remarkably higher than the lower zone.

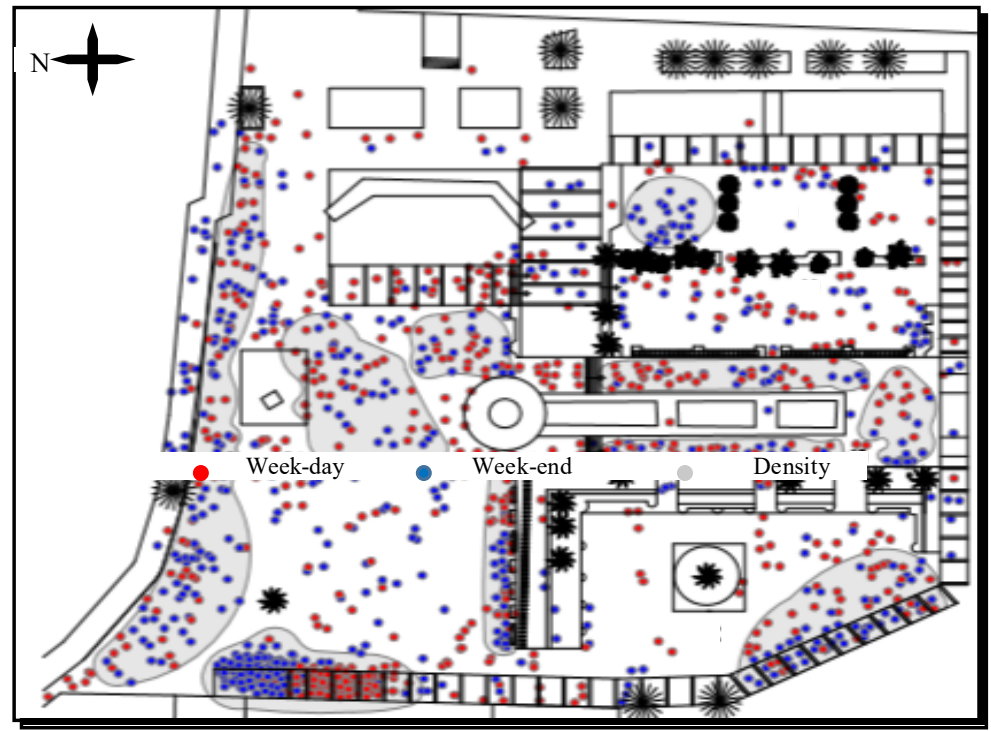

Fig. 3. Behavior mapping of static activities "sitting/ standing", and dynamic activities "movement" in five periods. People on the map are represented by dots.

The results (Tab. 2) also show that there is a segregation in the continuity of people's space use during the day. In the morning between 8 a.m. until 12 a.m. people's space use is increasing from 147 users to 271, and decreasing to 224 users in midday period. After midday period from 14p.m. more than 300 users in plaza, however the major activities in plaza is the dynamic activity "walking".

People's responses divided into three different groups (siting-standing and walking), according to the user's activity during the questionnaire survey. There were 104 respondents during the two days. From 104 respondents, 63 respondents are standing, 15 respondents are siting and 26 respondents are walking.

Firstly, about the use of plaza, the respondent of three groups are confirmed that they prefer to use the plaza in the morning, from 8 a.m. to 10 a.m. and, in the evening after 16 p.m. Secondly, about the raison to use the plaza, 43 respondents justified their space's use for relaxation, 34 respondents because the plaza is near to the majority of equipment; bank, police and post office, 27 respondents because the plaza offers little service such us small shops. Finally, the responses about the user's frequency, the majority of users 70 respondents pass by daily and several 
time to the plaza, 20 respondents confirmed that they passed few time (per month) and 14 respondents they passed rarely.

Tab. 1. Shows the number of static people (sitting/standing people) and dynamic people (walking) according to subspaces of El-Houria plaza in five periods on two days (week day and week-end).

\begin{tabular}{|c|c|c|c|c|c|c|c|c|c|c|}
\hline Time & \multicolumn{2}{|c|}{ 8-10 a.m. } & \multicolumn{2}{|c|}{ 10-12 a.m. } & \multicolumn{2}{|c|}{ 12-14 p.m. } & \multicolumn{2}{|c|}{ 14-16 p.m. } & \multicolumn{2}{|c|}{ 16-18 p.m. } \\
\hline 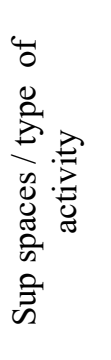 & 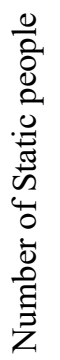 & 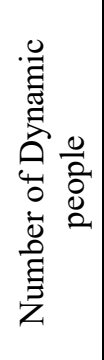 & 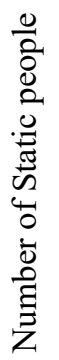 & 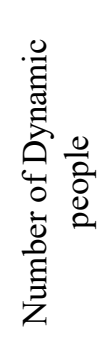 & 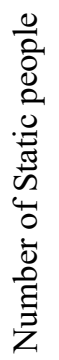 & 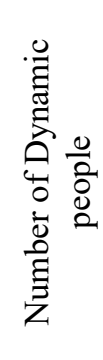 & 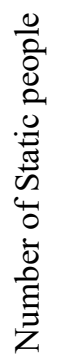 & 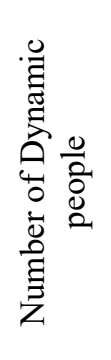 & 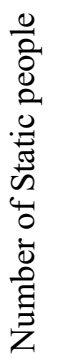 & 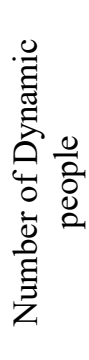 \\
\hline $\begin{array}{c}\text { Higher } \\
\text { space }\end{array}$ & 37 & 61 & 64 & 82 & 68 & 72 & 86 & 71 & 82 & 128 \\
\hline $\begin{array}{c}\text { Lower } \\
\text { space }\end{array}$ & 10 & 39 & 41 & 84 & 19 & 65 & 52 & 67 & 59 & 126 \\
\hline Total & & 47 & & 71 & & 24 & & 276 & & 95 \\
\hline
\end{tabular}

The obtained results from people's response justified the results obtained from behavior mapping. The segregation in the continuity of activities and the preference to use the plaza in particular periods morning and evening are justified the decreasing of people's occupancy in the midday period, However the majority of people cross the plaza due to strategic location in the city center, not because the plaza is offer higher quality of service like relaxing. Gehl (1987) in his book "life between buildings" confirmed that when outdoor areas are of poor quality, only strictly necessary activities occur and when the outdoor areas are of high quality, necessary activities take place with approximately the same frequency though they clearly tend to take a longer time, because the physical conditions are better.

On projection of the finding of Gehl on our study, nevertheless the strategical location of plaza and the good connectivity with the urban structure of city, the main necessary activity in plaza is the dynamic activity "walking", the plaza does not frequent by people as it should be, and people's frequency is depending on the time of the day, which means that the plaza has poor functionality. Beside the poor functionality, the segregation in the occupancy of plaza between the upper zone 
and the lower zone leads also to thinking about its layout design and its physical environment.

As results the plaza does not response to user's needs because it has a poor quality.

\section{Conclusion}

This study is addressed to planners, designers, decision makers and authorities. The study presents an investigation method of human behaviors in outdoor urban space and contribute affectively to understand the meanings of people's behaviors and user pattern which lead to a successful design.

The findings from this study proved that outdoor activities have a direct relationship with the quality of outdoor space, this means that human behavior in any urban space has to be tested and carefully studied

Thus, in this study the observation and the questionnaire survey were carried on March. March represent the transition period between winter and summer in the city of Biskra Algeria, it will be more effective to carried the study on the hot season where the mean maximum daily temperature is $40{ }^{\circ} \mathrm{C}$. So it can be also concluded that user pattern in outdoor urban space does not totally depend on the spatial patterns of space, and rather there are may be other factors which come into effect.

Future studies will be related not only to the user pattern and the outdoor urban space but also include the assessment of outdoor comfort and the perception of comfort.

\section{References}

1. Aghostin-Sangar, V. (2007), Human behaviour in public spaces (Doctoral dissertation, Faculty of Built Environment, University of New South Wales).

2. Bada, Y. (2012), The Impact of Visibility on Visual Perception and Space Use: The Case of Urban Plazas in Biskra, Université Mohamed Khider-Biskra, Syntax symposium (pp. 545-553).

3. Carr, S., Stephen, C., Francis, M., Rivlin, L.G., \& Stone, A.M. (1992), Public space, Cambridge University Press.

4. Choi, A.S., Kim, Y.O., Oh, E.S., \& Kim, Y.S. (2006), Application of the space syntax theory to quantitative street lighting design, Building and environment, 41 (3), 355366. https://doi.org/10.1016/j.buildenv.2005.01.026 
5. de Arruda Campos, M.B., \& Golka, T. (2005), Public spaces revisted: a study of the relationship between patterns of stationary activity and visual fields, Proceedings of the 5th international space.

6. Gehl, J. (2011), Life between buildings: using public space, Island press.

7. Goličnik, B., Thompson, C.W. (2010), Emerging relationships between design and use of urban park spaces, Landscape and urban planning, 94 (1), 38-53. https://doi.org/10.1016/j.landurbplan.2009.07.016

8. Hillier, B., Hanson, J. (1984), The Social Logic of Space Syntax.

9. Jayasundara, N., Botheju, P., Spatial patterns and human behaviors: A study of urban public spaces in Kandy.

10. Li, S. (1994), Users' behaviour of small urban spaces in winter and marginal seasons, Architecture and Behaviour, 10 (1), 95-109.

11. Martinelli, L., Lin, T. P., \& Matzarakis, A. (2015). Assessment of the influence of daily shadings pattern on human thermal comfort and attendance in Rome during summer period. Building and Environment, 92, 30-38. https://doi.org/10.1016/j.buildenv.2015.04.013

12. Marušić, B.G. (2011), Analysis of patterns of spatial occupancy in urban open space using behaviour maps and GIS, Urban design international, 16 (1), 36-50. https://doi.org/10.1057/udi.2010.20

13. Nasar, J.L., Yurdakul, A.R. (1990), Patterns of behaviour in urban public spaces, Journal of Architectural and Planning Research, 7 (1), 71-85. https://www.jstor.org/stable/43028946

14. Nikolopoulou, M., Baker, N., Steemers, K. (2001), Thermal comfort in outdoor urban spaces: understanding the human parameter, Solar energy, 70 (3), 227-235. https://doi.org/10.1016/S0038-092X(00)00093-1

15. Thorsson, S., Honjo, T., Lindberg, F., Eliasson, I., Lim, E.M. (2007), Thermal comfort and outdoor activity in Japanese urban public places, Environment and Behavior, 39 (5), 660-684. https://doi.org/10.1177/0013916506294937

16. Whyte, W.H. (2012), City: Rediscovering the center, University of Pennsylvania Press.

17. Zacharias, J., Stathopoulos, T., Wu, H. (2001), Microclimate and downtown open space activity, Environment and Behavior, 33 (2), 296315.https://doi.org/10.1177/0013916501332008 